\title{
Scale-up protein separation on novel stainless steel wide bore toroidal columns in the type-J counter-current chromatograph
}

\section{Yue Hugh Guan a,b*, Peter Hewitson ${ }^{\mathrm{c}}$, Remco N.A.M. van den Heuvel ${ }^{\mathrm{c}}$, Yan Zhao $^{\text {a,b }}$, Rick P.G. Siebers ${ }^{\mathrm{d}}$, Ying-Ping Zhuang ${ }^{\mathrm{a}, \mathrm{b}}$, Ian Sutherland ${ }^{\mathrm{c}}$}

${ }^{\text {a }}$ State Key Laboratory of Bioreactor Engineering, \&The College of Biotechnology, East China University of Science \& Technology, Shanghai 200237, China

${ }^{\mathrm{b}}$ Shanghai Collaborative Innovation Center for Biomanufacturing Technology, 130 Meilong Road, Shanghai 200237, China

'Institute of Environment, Health and Societies, Brunel University London, Uxbridge, Middlesex, UB8 3PH, UK

${ }^{\mathrm{d}}$ Department of Applied Physics, Fontys University of Applied Sciences, Rachelsmolen 1, 5600 AH Eindhoven, The Netherlands

*Corresponding author: Y.H. Guan, State Key Laboratory of Bioreactor Engineering, East China University of Science \& Technology, Shanghai 200237, China

Tel: +86 (0)21 64253032;

Fax: $+86(0) 2164253702$

Email: y.h.guan@ecust.edu.cn, or hugh.guan@hotmail.com (Y.H. Guan)

Keywords: Counter-current chromatography; aqueous two-phase systems; protein separation and purification; toroidal column; scale up chromatography column; liquid-liquid chromatography 


\begin{abstract}
Manufacturing high-value added biotech biopharmaceutical products (e.g. therapeutic proteins) requires quick-to-develop, GMP-compliant, easy-to-scale and cost effective preparatory chromatography technologies. In this work, we describe the construction and testing of a set of 5$\mathrm{mm}$ inner diameter stainless steel toroidal columns for use on commercially available preparatory scale synchronous J-type counter-current chromatography (CCC) machinery. We used a $20.2 \mathrm{~m}$ long column with an aqueous two-phase system containing 14\% (w/w) PEG1000 and 14\% (w/w) potassium phosphate at $\mathrm{pH} 7$, and tested a sample loading of $5 \%$ column volume and a mobile phase flow rate of $20 \mathrm{ml} / \mathrm{min}$. We then satisfactorily demonstrated the potential for a weekly protein separation and preparation throughput of $c a .11 \mathrm{~g}$ based on a normal weekly routine for separating a pair of model proteins by making five stacked injections on a single portion of stationary phase with no stripping. Compared to our previous $1.6 \mathrm{~mm}$ bore PTFE toroidal column, the present columns enlarged the nominal column processing throughput by nearly 10. For an ideal model protein injection modality, we observed a scaling up factor of at least 21 . The 2 scales of protein separation and purification steps were realized on the same commercial CCC device.
\end{abstract}




\section{Introduction}

There are various purposes to isolate and purify proteins, cellular and sub-cellular particles. Presently in biopharmaceutical industry, there is a general lack of suitable protein separation downstream technologies, and therefore a genuine need in seeking them [1].

Although counter-current chromatography (CCC) has achieved huge successes in separating small molecules on large scale, the challenge in using $\mathrm{CCC}$ in resolving proteins using aqueous two-phase systems (ATPS) has been with us for some 3 decades [2]. ATPSs are preferred because they differentiate proteins by partition coefficient and preserve protein biological activities. Two requirements need to be satisfied particularly for CCC using ATPS. First, the stationary phase of an ATPS is subject to rather high drag force (i.e. a friction force) exerted on the stationary phase from the mobile phase. This is different to most of aqueous-organic two-phase systems where the difference in hydrophobicity tends to dictate the level of stationary phase retention - hydrophilic low and hydrophobic high. Second, the molecules to be separated need to be cyclically partitioned between the stationary and the mobile phases over each rotation (1000 cycles per min at $1000 \mathrm{rpm}$ rotation speed), but this process slows down considerably with large molecules (e.g. proteins) unless a much enhanced mixing condition can be created $[3,4]$. With a portfolio of innovative CCC columns being explored [2,5-7], their scaling-up has been justified through increasing the column diameter [8], the same as HPLC.

Up to now, positive results for protein separation in this area have been obtained in the following situations, (a) use of cross-axis CCC machinery where the rotation locus on the rotor is perpendicular to the rotation plane of the column $[9,10]$, (b) adoption of toroidal column on synchronous J-type CCC machinery [7,11], (c) construction of various spiral columns on J-type machinery [2,12], and development of non-synchronous J-type CCC machinery $[13,14]$. In parallel, use of centrifugal partition chromatography (CPC) for protein separation using ATPS underwent a period of enthusiasm as well [15]. Shortcomings for the CPC approach are the stringent requirements for sample pre-treatment before injection and stationary phase stripping problem [15].

We have developed a 1.6-mm bore size toroidal column, operated in a usual J-type CCC machinery [6,7]. Historically, toroidal column was one of the early CCC column geometries [11,1623], and a summarization is made in Table 1. The working of protein separation using the toroidal column has been pursued by Ito and others $[3,7,20]$. Inarguably, the processing capacity developed has been for analytical usages except our 1.6-mm bore size column which was semi-prep. Even so, the mobile phase flow rate for the 1.6-mm ID column was typically operated at less than $1 \mathrm{ml} / \mathrm{min}$ and protein separation takes 4-5 hours.

We have preferred the commercially popular J-type CCC machinery due to reasons of simplicity in mechanical construction, ease of scaling-up, and affordable price [24]. In order to retain the 
ATPS stationary phase, the column geometry mounted on the CCC machinery needs to meet certain requirements $[6,12,25]$. Briefly, when the two immiscible phases (either two aqueous or two organic phases) have similar hydrophilicity or hydrophobicity, mobile phase flow tends to drag out the intended stationary phase and thus may considerably reduce stationary phase retention [12]. The toroidal coil relies mainly on centrifugal force on half circle of each coil turn and thus usually the maximal stationary phase retention would be less than 50\% [3]. The J-type planetary motion contributes to the mixing between the mobile and stationary phases. In general, both stationary phase retention level and phase mixing intensity are less influenced by the similarity or dissimilarity in hydrophobicity between the mobile and the stationary phases. Therefore, there is a compelling reason to use this type of column on J-type CCC machinery with ATPS.

We earlier on [25] compared the 5mm toroidal coil chromatography (TCC) with the CPC [15] and demonstrated that the TCC approach can solve the stripping problem. The present work takes further of our prior work where 1.6-mm bore size PTFE toroidal coil was developed and experimentally tested, and details the winding and construction of the 5-mm bore size toroidal columns, and developes a protocol in manufacturing such toroidal CCC columns. Such newly developed columns underwent experimentations for examining their capability in retaining the intended stationary phase of an ATPS and for separating a pair of selected model proteins.

\section{Construction of stainless steel 5-mm bore toroidal columns}

The primary structure of a toroidal column is a helical coil (Fig. 1A) and its secondary structure again is a helical coil perpendicular to the rotor shaft (Fig. 1B). For this instrument both are wound as right handed coils. In order to maximise the column length in the available bobbin winding space, we chose a type 316 stainless steel tube with ID $5 \mathrm{~mm}$ and $0.5 \mathrm{~mm}$ wall thickness (Aalco Metals Limited, UK). This thin walled tubing was wound into a helical coil (20 mm OD and 12 mm ID) under a high internal pressure to minimise collapse of the stainless steel tubing which became oval in cross-section $(3.0 \times 6.5 \mathrm{~mm})$. It is possible such coil flattening is beneficial to increasing phase mixing intensity. Dynamic Extractions Ltd (Slough, UK) constructed two similar columns by winding this primary helix onto a bobbin to form the secondary helix. These columns were integrated into a High Performance DE-Midi rotor for mounting in a DE-Midi instrument (Slough, UK). This instrument is capable of rotation speeds of up to 1400rpm to give a system capable of commercial exploitation (column volumes $334 \mathrm{ml} \mathrm{(317} \mathrm{ml}$ active loop volume) and 338 $\mathrm{ml}$ (321 active loop volume), loops 405 and 404, lengths 20.2 and $20.1 \mathrm{~m}$ respectively). The final coil/column configuration is as shown in Figure $1 \mathrm{~b}$ of [25] and construction protocol as detailed and illustrated in the supplementary information.

\section{Experimental}




\subsection{Phase system preparation}

The ATPS of $12.5 \%(\mathrm{w} / \mathrm{w})$ polyethylene glycol (PEG) 1000 (Sigma-Aldrich P3515) and $12.5 \%$ (w/w) $\mathrm{K}_{2} \mathrm{HPO}_{4}$ (Sigma-Aldrich P3786) in distilled water was prepared by dissolving $125 \mathrm{~g}$ of PEG 1000 and 125g of anhydrous dibasic potassium phosphate in $750 \mathrm{~g}$ of distilled water aided by a magnetic stirrer. This ATPS system is often shortened as "12.5\% ATPS" in this paper. The physical properties of $12.5 \%$ ATPS system are: settling time $130 \mathrm{~s}$, density difference $48.8 \mathrm{~kg} / \mathrm{m}^{3}$, interfacial tension $0.095 \mathrm{mN} \mathrm{m}^{-1}$, upper phase viscosity $4.84 \mathrm{mPa} \mathrm{s}$, and low phase viscosity $1.71 \mathrm{mPa} \mathrm{s}[6,7]$. The partition coefficients for the proteins or the dipeptides (see below) were measured and have been reported in Table 1 of [6].

The ATPS of $14 \%(\mathrm{w} / \mathrm{w})$ polyethylene glycol (PEG) 1000 (Sigma-Aldrich P3515) and $14 \%\left(\mathrm{w} / \mathrm{w}\right.$ ) potassium phosphate at $\mathrm{pH} 7.2$ (with anhydrous potassium phosphate dibasic $\mathrm{K}_{2} \mathrm{HPO}_{4}$ being Sigma-Aldrich P3786 and anhydrous potassium phosphate monobasic $\mathrm{KH}_{2} \mathrm{PO}_{4}$ being SigmaAldrich P0662) in distilled water was prepared by dissolving $280 \mathrm{~g}$ of PEG 1000, $221.35 \mathrm{~g}$ of $\mathrm{K}_{2} \mathrm{HPO}_{4}$, and $58.65 \mathrm{~g}$ of $\mathrm{KH}_{2} \mathrm{PO}_{4}$ in $1440 \mathrm{~g}$ of distilled water aided by a magnetic stirrer. This ATPS system is often shortened as "14\% ATPS" in this paper. The physical properties of $14 \%$ ATPS system are: settling time $104 \mathrm{~s}$, density difference $91.3 \mathrm{~kg} / \mathrm{m}^{3}$, interfacial tension $5.75 \mathrm{mN} \mathrm{m}^{-}$ 1, upper phase viscosity $8.95 \mathrm{mPa} \mathrm{s}$, and low phase viscosity $2.69 \mathrm{mPa}$. The liquid phases thus formed were allowed to equilibrate at room temperature $\left(\mathrm{ca} .20^{\circ} \mathrm{C}\right)$ in a separation funnel for at least $4 \mathrm{hr}$.

\subsection{Sample preparation}

Chicken egg white lysozyme (L6876) and equine skeletal muscle myoglobin (M0630) were obtained from Sigma-Aldrich. Dipeptides, H-His-Gly-OH (His-Gly; catalogue number G-2305) and H-Val-Tyr-OH (Val-Tyr; catalogue number G-3585) were from Bachem (UK), St. Helens, UK. Myoglobin and lysozyme, either individually or in the same liquid phase, each at $2.2 \mathrm{mg} / \mathrm{ml}$, were prepared in the mobile phase of either $12.5 \%$ ATPS or 14\% ATPS. The dipeptides, His-Gly and Val-Tyr, were prepared either as single components or as mixtures in the mobile phase of the ATPS at concentrations of $12.5 \mathrm{mg} / \mathrm{ml}$. A sample solution was injected into the CCC system using an injection loop with the required volume [7].

\subsection{Running procedure}

Before initiating the chromatography software, pump the stationary phase into the CCC columns. With the CCC machinery in rotating motion and the software running, pump the mobile phase (usually lower phosphate-rich phase) into the column in the direction opposite to the CCC column rotation. Following mobile phase breakthrough and the subsequent UV signal stabilization at 
wavelength $220 \mathrm{~nm}$, inject the sample into the CCC column. The eluant was collected and its volume was recorded to measure both the stationary phase retention and the amount of stationary phase stripping from the column following sample injection and/or during the consecutive protein separation runs. It is worth pointing out that, although the lower mobile phase flows in the head-totail direction, it is however more important to arrange its orientation against the rotor's rotation of the CCC machinery [3,7].

The CCC Centrifuge was operated at $20 \pm 1^{\circ} \mathrm{C}$ via in situ temperature control by external circulation of cooling water. Mobile phase was pumped into the $\mathrm{CCC}$ column using a Knauer HPLC System, comprising an interface box, a Knauer K-6 electrical valve drive, two preparative K1800 HPLC pumps with 250-ml head each (for the upper and lower phases respectively) (Berlin, Germany). This system is annexed to a Gilson UV/VIS-151 spectrophotometer with a preparative flow cell (Middleton, WI, USA) to continuously monitor the UV absorption of the eluant. Chromatography data retrieval and analysis were performed on Waters Alliance Empower software package (Knauer, Berlin-Zehlendorf, Germany). A sample loop for sample injection, either of 16.2$\mathrm{ml}$ (i.e. $5 \%$ column volume) or of 5-ml (i.e. $1.5 \%$ column volume), was used in the experiment.

At the end of each CCC run, the volume of stationary phase retained in the toroidal column $\left(S_{f}\right)$ was measured following a thorough depletion of the liquid phases in the column by $\mathrm{N}_{2}$ gas, and $S_{f}$ was calculated as,

$S_{f}=\frac{V_{s}}{V_{c}} \times 100 \%$

where $V_{s}$ is the stationary phase volume remaining in the toroidal column during a CCC usage.

The resolution between the two neighbouring peaks on a chromatogram, $R_{s}$, was estimated by,

$$
R_{S}=\frac{2\left(\mathrm{t}_{2}-\mathrm{t}_{1}\right)}{w_{b 1}+w_{b 2}}
$$

where $t_{1}$ and $t_{2}$ are the elution times corresponding to the first and the second peaks from sample injection, and $w_{b 1}$ and $w_{b 2}$ are peak widths (measured by the elution time) for the two peaks respectively. In our calculations, the peak position for either $t_{1}$ or $t_{2}$ was determined by the intercept point of the two tangent lines for the left and right sides of a chromatogram peak respectively. $w_{b 1}$ or $w_{b 2}$ was taken as the length on the chromatogram baseline intercepting the above two tangent lines.

From the obtained chromatogram, the separation efficiency was also computed and expressed in terms of theoretical plate (TP) number as,

$$
\mathrm{N}=\left(\frac{4 t}{w_{b}}\right)^{2}
$$


where $N$ denotes the theoretical plate number, $t$ is the elution time, and $w_{b}$ the peak width expressed by the elution time.

The partition coefficient of a protein or a dipeptide (the $K$ value) is defined as its concentration ratio between the upper and the lower phases of an ATPS. The $K$-value is defined as the concentration ratio between the stationary upper phase and the mobile lower phase for the molecule concerned.

When the mobile lower phase flows against the rotating orientation, better phase mixing results by the Coriolis force (termed Coriolis force parallel). However, when the mobile lower phase flows in the rotating orientation, poor mixing results (termed Coriolis force crossing) [7,20]. Consequently, the present work focussed on the situation when the Coriolis force is parallel to the effective coil segments.

\section{Results and Discussion}

Scale-up from the 1.6- $\mathrm{mm}\left(r_{1.6 \mathrm{~mm}}\right)$ to the $5-\mathrm{mm}\left(r_{5 \mathrm{~mm}}\right)$ bore size by keeping the linear velocity of the mobile phase, their mobile phase flow rates (i.e. $F_{1.6 \mathrm{~mm}}$ and $F_{5 \mathrm{~mm}}$ ) are related by,

$F_{5 \mathrm{~mm}}=\left(\frac{r_{5 \mathrm{~mm}}}{r_{1.6 \mathrm{~mm}}}\right)^{2}$

For mobile phase flow rates of $0.62,1.25,2.5 \mathrm{ml} / \mathrm{min}$ for our previous $1.6-\mathrm{mm}$ narrow bore toroidal column [6], the corresponding flow rates for the present 5-mm wide bore column are 6.1, $12.3,30.6 \mathrm{ml} / \mathrm{min}$ respectively.

\subsection{ATPS stationary phase retention in the 5-mm bore size toroidal column}

Stationary phase retention $S_{f}$ for $12.5 \%$ ATPS at mobile phase flow rates of 30.6, 12.25 and $6.08 \mathrm{ml} / \mathrm{min}$ respectively were measured for the wide bore column. Our results (data not given) show that stationary phase retention out of the narrow bore coil and that out of the wide bore coil are the same. This indicates that (a) the effect of the column bore size on stationary phase retention is insignificant, and (b) in the linear flow rates concerning the work using either the 1.6-mm bore size or the 5-mm bore size tubing, the effect of mobile phase flow rate is insensitive to the stationary phase retention for the ATPS chosen.

\subsection{Separation on model proteins using the 5-mm bore size toroidal columns}

Protein separation was made using the myoglobin and lysozyme protein pair $[6,7,27,28]$ and initiated by injecting either myoglobin or lysozyme but not both. By plotting the resulting chromatograms on the same time abscissa, the potential is revealing in separating the two proteins 
at $10 \mathrm{ml} / \mathrm{min}$ lower mobile phase flow when stationary phase retention is at ca. $36.7 \%$ using $14 \%$ ATPS (Fig. 2A) with a resolution $R_{S}=1.68$. Though stationary phase retention is reduced to $24 \%$ at $20 \mathrm{ml} / \mathrm{min}$ mobile phase flow rate, a decent level of separation for these two proteins remains despite the resolution dropping to $R_{S}=0.86$ (Fig. $2 \mathrm{~B}$ ). In the reality test by injecting the 2-protein mixture, although stationary phase retention is reduced to $33.7 \%$, the separation resolution achieved is $R_{S}=1.41$ (Fig. $2 \mathrm{C}$ ) compared to 1.68 for the tandem injection. This difference is probably due to the reduced retention. Unfortunately, $12.5 \%$ ATPS does not seem to deliver a knock-out effect (Fig. 3D $-R_{S}=0.7$ ) with rotational speed of $800 \mathrm{rpm}$ but is comparable with the results at the equivalent linear flow in the $1.6 \mathrm{~mm}$ tubing [6] where the resolution is $R_{s}=0,8$.

The chromatogram for separating the 2 model proteins with upper PEG rich phase mobile is shown in Fig. 2E. This result supplements that in Fig. $2 \mathrm{C}$ where mobile phase is the lower phosphate rich phase. Protein separation is better when the less viscous lower salt phase is used as the mobile phase rather than the more viscous PEG upper phase.. Our result in Fig. 2E is broadly in agreement with the following documented results using CCC or CPC devices: (a) use of an eccentric coil assembly with 0.8 - $\mathrm{mm}$ or 1-mm bore size, a toroidal coil assembly with 1-mm bore size, or a helical column assembly with $1.5-\mathrm{mm}$ bore size, on a cross-axis CCC [14,29,30], (b) use of 2 spiral column assemblies with 1.0-mm, 1.5-mm or 2.0-mm bore size, and a spiral shape $2 \times 2.8$ mm mixer-settler on CCC systems [10,28,30,31], (c) use of a coaxial multilayer column assembly with 0.8-mm bore size, or an eccentric coil assembly, on a nonsynchronous CCC [13], and (d) use of a CPC for the same protein pair separation [10,32]. Under the tested condition with the upper PEG phase being the stationary phase, the stationary phase retention $\left(S_{f}\right)$ remains to be $30.1 \%$ and this is suitable for protein separation. This result suggests that this scaled-up toroidal column is useful for protein separation in both lower and upper phase mobile using the type-J CCC with ATPSs.

The $10 \mathrm{ml} / \mathrm{min}$ flow rate for the present 5 -mm bore size toroidal column is largely comparable to the $1 \mathrm{ml} / \mathrm{min}$ flow rate for our previous $1.6-\mathrm{mm}$ bore size toroidal column. In addition, the length of the present 5-mm column is similar to the 25.8-m length "short" column for our 1.6-mm bore size column [6]. Conclusively, there has been no compromise of protein separation resolution after scaling up from the narrow to the present large bore size toroidal column.

The somewhat less satisfactory separation resolution for $12.5 \%$ ATPS is due partly to the low rotational speed/g field and partly to the column length restriction on the present 5-mm wide bore column. Fig. 3A shows that resolution is increased from Rs=0.7 (Fig 3D) to 1.1 as rotational speed increases from 800rpm (79g) to $1400 \mathrm{rpm}$ (241g). It also shows that, when the length of the 5-mm bore size column is doubled, protein separation resolution augments from $R_{S}=1.1$ to $R_{S}=1.6$ for $12.5 \%$ ATPS (Fig 3). This increase in separation resolution is slightly better than a theoretical 
prediction of $\sqrt{2} \cong 1.4$, and shows that the scaling-up has been generally in agreement with the theory. While these experiments were performed at $1400 \mathrm{rpm}$ rotation speed, there were no concerns from any high back pressure during operation. In addition to the improvement in separation resolution, interestingly the stationary phase retention shows an increase from $20.5 \%$ for the single-bobbin short toroidal column to $38.4 \%$ for the double-bobbin long toroidal column (Fig. 3).

When working with $12.5 \%$ ATPS, the effect of the rotation speed was examined for speeds at $800,1000,1200$ and $1400 \mathrm{rpm}$ for the CCC machinery, which has a rotor radius of $\mathrm{R}=11 \mathrm{~cm}$ and $\beta$-value in the range of $0.52-0.86$ (Fig. 4). These results show that increase in the rotation speed does not necessarily bring up the stationary phase retention to a satisfactory level. In contrast, the resulted improvement on the separation resolution, at least for this model protein pair, has been considerable. If we regard $800 \mathrm{rpm}$ rotation speed as the reference level, each stepwise increase for the rotor's rotation speed has been $25 \%, 20 \%$ and $16.7 \%$ respectively, and the corresponding protein separation resolutions are $R_{S}=0.24,0.64,1.06$, and 1.11 . In our earlier protein separation work using the narrow bore toroidal column with $25.8-\mathrm{m}, 53.5-\mathrm{m}$, and $86.6 \mathrm{~m}$ column lengths respectively, we mostly kept the rotation speed at $800 \mathrm{rpm}$ [7]. This was primarily based on our concern on high back pressure and on our intention for having better operation stability. For both the previous 1.6-mm narrow bore and the present 5-mm wide bore columns, the built-up back pressure does not seem to sensitively correlate with the column length (see Ref [7] and Fig. 3). However, increasing the rotor's rotation speed increases the back pressure as expected due to the increasing hydrostatic pressure (Fig. 4).

\subsection{Separation on model proteins using the 5-mm bore size toroidal columns with $14 \%$ ATPS}

It is worth stressing that both the previous 1.6-mm narrow bore and the present 5-mm wide bore toroidal columns were fitted into the same $\mathrm{J}$-type $\mathrm{CCC}$ bobbin for the radius range from $r_{\min }=$ $5.7 \mathrm{~cm}$ to $r_{\max }=9.5 \mathrm{~cm}$. There were 3 independent pieces of the narrow bore tubing for a single bobbin, with each being constructed using a single piece of PTFE tubing. Via connection, we had 3 column lengths (namely $25.7 \mathrm{~m}, 53.5 \mathrm{~m}$ and $86.6 \mathrm{~m}$ ) for selection. For the 5 -mm wide bore toroidal column, the maximal column length accommodated by the single bobbin was merely $21.7 \mathrm{~m}$, and this is close to the Short Column length of the narrow bore column with 25.7-m column length. For the 5-mm wide bore column, the maximal column length, $45.1 \mathrm{~m}$, can be obtained by serial connection of the toroidal columns mounted on 2 separate CCC bobbins. With the use of $12.5 \%$ ATPS, the best separation resolution for the 2 model proteins is $R_{s}=1.6$ at $1.5 \%(\mathrm{v} / \mathrm{v})$ column volume sample loading and $1400 \mathrm{rpm}$ rotation speed (Fig. 3B). As the protein separation resolution is sensitive to this rotation speed (Fig. 4), use of $1200 \mathrm{rpm}$ slightly compromises the protein 
separation resolution from $R_{S}=1.10$ (for $1400 \mathrm{rpm}$ ) to $R_{S}=1.06$ (for $1200 \mathrm{rpm}$ ). Furthermore, the present result is associated with the $1.5 \%(\mathrm{v} / \mathrm{v})$ sample loading and an increase of this sample loading mayreduce the protein separation resolution [7] but an increase to $5 \%(\mathrm{v} / \mathrm{v})$ has been demonstrated in [25].

To broaden the applicability for protein sample loading levels and to ensure a satisfactory and robust protein separation resolution using low rotation speed for the rotor, we feel appropriate to rely on 14\% ATPS for further demonstrating applications for the 5-mm wide bore toroidal column. As $14 \%$ ATPS is associated with a longer tie length on the ATPS phase diagram and so a better separation outcome is in anticipation [33].

With the use of $14 \%$ ATPS and at 5\% (v/v) sample loading, the protein separation chromatograms at a rotational speed of 800, 1000, and $1200 \mathrm{rpm}$ respectively are shown in Fig. 5. With lower mobile phase flow at $10 \mathrm{ml} / \mathrm{min}$, stationary phase retention hardly changes. The protein separation resolutions are $R_{S}=1.45$ (for $800 \mathrm{rpm}$ ), $R_{S}=1.69$ (for $1000 \mathrm{rpm}$ ), and $R_{S}=1.61$ (for $1200 \mathrm{rpm}$ ) respectively. Evidently, increasing rotation speed improves the separation resolution notably in the 800-1000 rpm range, but above $1000 \mathrm{rpm}$ this effect diminishes considerably.

\subsection{The wide and the narrow bore toroidal columns: a comparison}

A decent stationary phase retention is necessary for protein separation, but still not sufficient $[4,6]$. To resolve large molecules like proteins, phase mixing intensity needs to be high. If the molecules to be resolved by the CCC system are well mixed - which appears to be the case in the present CCC machinery due to the Gaussian shaped peaks - their K-values virtually determine the elution outcome. For the 1.6-mm narrow bore toroidal column, we successfully probed the phase mixing intensity by comparing the dipeptide and protein chromatograms [6,7]. The small dipeptides chosen are similar to their large protein counterparts in hydrophilicity, and so partition in ATPSs similarly. Notably, the K values for dipeptide His-Gly and protein Lysozyme are nearly the same in the ATPSs adopted. Similar CCC separation resolutions for the dipeptides and proteins indicate intensive phase mixing whereas poor protein resolution indicates insufficient mixing. For large protein molecules which have molecular weight nearly 70 times their dipeptide counterparts, unless the CCC system provides much more intensive phase mixing, their separation resolution has to be lower than that for the dipeptides.

The measured separation resolutions on the present 5-mm bore size column are 1.9 and 2.4 with lower mobile phase flow rates of 3.75 and $5 \mathrm{ml} / \mathrm{min}$ respectively using $12.5 \%$ ATPS for the dipeptide pair, His-Gly (K=1.9) and Val-Tyr (K=4.0) (Fig. 6). According to eq. (5) above, these two flow rates correspond respectively to $0.38 \mathrm{ml} / \mathrm{min}$ and $0.51 \mathrm{ml} / \mathrm{min}$ for the $1.6-\mathrm{mm}$ bore size, which is in the range where the best protein separation was observed for this narrow bore column [6]. For 
the 5-mm wide bore column at $800 \mathrm{rpm}$ rotation speed, the proteins are not well resolved (Fig. 2D $R_{S}=0.7$ ) whilst the dipeptides can (Fig. 6). For the 1.6-mm narrow bore toroidal coil and using $12.5 \%$ ATPS, the theoretical plate numbers for His-Gly and lysozyme in the same condition are 224.4 TP and 165 TP respectively [7]. For the present 5-mm wide bore column and using 14\% ATPS, the theoretical plate numbers for lysozyme are 43.3 at $800 \mathrm{rpm}$ rotation speed, 83.0 at 1000 rpm, and 141.0 at $1200 \mathrm{rpm}$ (Fig. 5). At $800 \mathrm{rpm}$ rotation speed, His-Gly is associated with a theoretical plate number of 47 at $5 \mathrm{ml} / \mathrm{min}$ mobile phase flow rate and that of 103 at $10 \mathrm{ml} / \mathrm{min}$ mobile phase flow rate (the 14\% ATPS chromatogram is not shown). When looking into the effect of bore size increase on protein separation, it appears that there has been a small drop in the separation resolution. This can be reflected notably by the following 2 illustrative examples. For the 1.6-mm narrow bore column, rather successful protein separation was achieved using 12.5\% ATPS at rotation speed of merely $800 \mathrm{rpm}$. However, for the $5-\mathrm{mm}$ wide bore column, decisive and robust protein separation was achieved using 14\% ATPS at rotation speed of 1000-1200 rpm. Even though one takes into consideration the effect of the column length (Table 1), it still appears that there has been a small drop in the protein resolution power for the wide bore column.

After all, this drop in protein resolution from the narrow to the wide bore column has been small and can be largely compensated by running the separation process at 1000-1200 rpm rotation speed (as compared to $800 \mathrm{rpm}$ for the narrow bore column) thanks to the use of stainless steel material for the present wide bore column.

Our present work has essentially provided 2 application choices to the users for protein separation and purification using the 5-mm wide bore toroidal column. The first choice is to serially connect the 2 short columns mounted on 2 separate yet weight balanced bobbins using $12.5 \%$ ATPS. The second choice offered is to run 2 short parallel columns simultaneously using 14\% ATPS.

There are both advantages and disadvantages for either option. The advantage for having 2 separate, parallel short toroidal columns includes short chromatography running time and doubled processing capacity, but the downside is to rely on an ATPS having higher PEG and higher salt concentrations. In contrast, the advantage for having the long toroidal column is to use an ATPS with low PEG and salt concentrations, but its disadvantage will be a longer chromatography running time and the halved productivity when compared with the 2 short toroidal columns.

Our opinion on these 2 application choices is that the short column system obviously is more desired and efficient for manufacturing. In Fig. 7 is shown a set of robust testing outcome for this short toroidal column system. The single bobbin, short column is operated with $14 \%$ ATPS and the lower mobile phase flows at $20 \mathrm{ml} / \mathrm{min}$ in this experiment. Once dynamic equilibration is reached (i.e. the stationary phase does not flow out of the toroidal column), the lysozyme-myoglobin sample was injected into this chromatographic column in a 20-min interval for five consecutive times. In 
the subsequent 110-min time period, we obtained 5 sets of identical chromatograms, showing the separation of these 2 proteins within 30 min. This means that the second sample injection can be made even before the first lysozyme fraction is eluted out of the toroidal column. In principle, this in-tandem 20-min cyclic sample injection is legitimate as the components at the different location along the chromatographic column do not bear any chance for back mixing.

The results in Fig. 7 show unambiguously that there has been no detectable loss of the stationary phase over the 110-min time period, and so indicate that fresh sample injection at the level demonstrated does not disturb the reached dynamic balance between the stationary and the mobile phases inside the rotating toroidal column. This experiment also demonstrates an impressive protein separation quality potentially for a protein manufacturing process where the separation resolution being $R_{S}=1.2$. This 20 -min repeated sample injection into the wide bore toroidal column on the $\mathrm{J}$ type CCC testified and then vindicated the performance robustness of this new protein preparation technology. In detail, these results indicate that, provided the wanted and unwanted components can be duly eluted, the productivity of this CCC technology could be maximized through such regular, repeated sample injection to boost the productivity on a preparative or manufacturing footing.

A caution however needs to be made at this end. Although stainless steel (type 316) column and tubing are still common for HPLC systems, high concentrations of acids or halogenated salts should however be avoided for this type of column material. Fortunately, such knowledge and know-how are well developed with the HPLC manufacturers and vendors. Compared to existing spiral columns for protein separation, the manufacturing costs for toroidal columns are not necessarily high and/or the time required long. Nevertheless, it is not difficult to work out the specified preparation time and costing for a specified country. Alternative to the stainless steel column reported in this work, the column could also be made from inexpensive PTFE tubing by embedding it in epoxy resin in a metal cylindrical case for resisting back pressure of ca. 300 psi.

\section{Conclusions}

Our previous work successfully constructed and developed an innovative narrow bore toroidal column with 1.6-mm column diameter for J-type CCC for separating the model protein pair myoglobin and lysozyme. The separation system and operation condition established are: $12.5 \%$ ATPS, lower phase mobile at $0.62 \mathrm{ml} / \mathrm{min}$, flow orientation against column rotation (i.e. Coriolis effect in parallel), column length of $53.5 \mathrm{~m}$, sample loading at $5 \%(\mathrm{v} / \mathrm{v})$ column volume, $800 \mathrm{rpm}$ rotation speed, and operation at room temperature. It takes $200 \mathrm{~min}$ to resolve the 2 model proteins [6,7]. For a laboratory operating regime with 10-hr CCC daily operation time, 14-hr daily downtime, and 5 weekly working days, weekly attainment for each of the 2 proteins would be $0.261 \mathrm{~g}$. This estimation is based on using only a single bobbin and so, based on a setting using 2 weight balanced 
toroidal columns in parallel, we would expect a weekly capacity of $0.521 \mathrm{~g}$ per machinery for each of the two model proteins.

Our present work constructed and tested a pair of wide bore toroidal columns with 5-mm column diameter. In separating the same model protein pair, the phase system and operation condition established are: 14\% ATPS, lower phase mobile at $20 \mathrm{ml} / \mathrm{min}$, flow orientation against column rotation (i.e. Coriolis effect in parallel), column length of 20.1 and $20.2 \mathrm{~m}$, sample loading at 5\% $(\mathrm{v} / \mathrm{v})$ column volume, $1400 \mathrm{rpm}$ rotation speed, and operation at room temperature. It takes $30 \mathrm{~min}$ to resolve the 2 model proteins. For a laboratory or a pilot plant with 10 -hr CCC operation time and 14-hr downtime on a daily basis, and 5 working days on a weekly basis, attainment of $5.5 \mathrm{~g}$ of each of the 2 proteins would be predictable. This optimistic estimation is based on using only a single bobbin and for separating a pair of model proteins. Based on the setting with 2 weight balanced toroidal columns yet used in parallel in the CCC machinery, we anticipate a weekly capacity of $11 \mathrm{~g}$ for each of the two model proteins. Although this model may well be over-simplified to the reality, it however pinpoints the potential of this technology as a powerful and high-throughput downstream processing unit operation platform for manufacturing high-value added biologics.

Compare the 2 bore sizes, it is possible that we have scaled up the toroidal coil protein processing capacity by a factor of 21 . In this sense, the merit of this scaling-up project over our previous studies with $1.6 \mathrm{~mm}$ bore tubing has been compelling. With regards to toroidal columns for CCC machinery, Table 1 shows that the 5-mm bore size stainless steel toroidal column is the largest reported in literature and in commercial news.

As a horizontal comparison, the spiral geometry column developed by Ito $[2,27,28]$ is likely to have higher sample processing capacity than our narrow bore toroidal column [6,7], but is almost certain to have lower capacity than our present wide bore toroidal column. For protein separation, the presently reported mobile phase flow rate of $20 \mathrm{ml} / \mathrm{min}$ is unique, and this is so for all the reported CCC columns and devices using ATPS, including cross axis device and spiral column. The only exception is a CPC operation with 429-ml column volume, which generated sound protein separation at $5 \mathrm{ml} / \mathrm{min}$ mobile phase flow yet suffered from gradual loss of the stationary phase at $10 \mathrm{ml} / \mathrm{min}$ (the stationary phase was completely stripped off at $20 \mathrm{ml} / \mathrm{min}$ [15]. It is worthwhile to point out that, even at $20 \mathrm{ml} / \mathrm{min}$ with a column volume of $337.8 \mathrm{ml}$, our $5-\mathrm{mm}$ bore size toroidal column does not register measurable loss of stationary phase throughout the 5 consecutive sample injections.

We confidently believe that a new competitive protein separation technology has been developed potentially for the fast growing modern biopharmaceutical industry. Application projects are being conducted using samples realistic to or coming from this industry. In addition, this new technology is now available to laboratory level preparation for many enzymes for research and development. 
This would then provide incentives for further scaling-up this technology to kilogram level protein preparation in the near future.

\section{Acknowledgements}

We acknowledge financial support of the BBSRC Grant number BB/FOF/206. YHG and YZ also acknowledge financial support by National Basic Research Program (973 Program 2013CB733600). Ms Yan Zhao (School of Mechanical and Power Engineering) has been grateful to a Training Program of Innovation and Entrepreneurship for Undergraduates Grant Number X13219 by East China University of Science and Technology. Contribution and/or encouragement to this work from D. Fisher, T. Bunce, Ying-Dong Liu, Zheng-Tao Zhang, Li-Li Bai are greatly appreciated and acknowledged. YHG is grateful to technical support received from Qiuyun Deng of Shanghai Tauto Biotech Co Ltd. 


\section{References}

[1] A.A. Shukla, J. Thömmes, Recent advances in large-scale production of monoclonal antibodies and related proteins, Trends Biotechnol., 28 (2010) 253-261.

[2] Y. Ito, Spiral column configuration for protein separation by high-speed countercurrent chromatography, Chem. Eng. Processing, 49 (2010) 782-792.

[3] Y. Ito, Y. Ma, Effects of coriolis force on countercurrent chromatography,J. Liq. Chromatogr. Rel. Techniq. 21 (1998) 1-17.

[4] Y.H. Guan, R.N.A.M. van den Heuvel, Y.-P. Zhuang, Visualisation of J-type counter-current chromatography: A route to understand hydrodynamic phase distribution and retention, $\mathrm{J}$. Chromatogr. A, 1239 (2012) 10-21.

[5] Y.H. Guan, J. Smulders, D. Fisher, I.A. Sutherland, Spiral coils for counter-current chromatography using aqueous polymer two-phase systems, J. Chromatogr. A, 1151 (2007) 115-120.

[6] Y.H. Guan, E.C. Bourton, P. Hewitson, I.A. Sutherland, D. Fisher, The importance of column design for protein separation using aqueous two-phase systems on J-type countercurrent chromatography, Sep. Pur. Technol., 65 (2009) 79-85.

[7] Y.H. Guan, D. Fisher, I.A. Sutherland, Protein separation using toroidal columns by type-J synchronous counter-current chromatography towards preparative separation, J. Chromatogr. A, 1217 (2010) 3525-3530.

[8] I. Sutherland, P. Hewitson, S. Ignatova, New 18-1 process-scale counter-current chromatography centrifuge, J. Chromatogr. A, 1216 (2009) 4201-4205.

[9] K. Shinomiya, J.-M. Menet, H.M. Fales, Y. Ito, Studies on a new cross-axis performing countercurrent. I. Design of the apparatus, retention of the stationary phase, and efficiency in the separation of proteins with polymer phase systems, J. Chromatogr. 644 (1993) 215-229.

[10] K. Shinomiya, H. Kobayashi, N. Inokuchi, K. Kobayashi, H. Oshima, S. Kitanaka, K. Yanagidaira, H. Sasaki, M. Muto, M. Okano, Y. Ito, New small-scale cross-axis coil planet centrifuge: partition efficiency and application to purification of bullfrog ribonuclease, $\mathrm{J}$. Chromatogr. A, 1151 (2007) 91-98.

[11] Y. Ito, R.L. Bowman, Countercurrent chromatography with the flow-through centrifuge without rotating seals, Anal. Biochem. 85 (1978) 614-617.

[12] Y.H. Guan, D. Fisher, I.A. Sutherland, Model for spiral columns and stationary phase retention in synchronous coil planet centrifuges, J. Chromatogr. A, 1151 (2007) 136-141. 
[13] K. Shinomiya, Y. Kabasawa, K. Yanagidaira, H. Sasaki, M. Muto, T. Okada, Y. Ito, Protein separation by nonsynchronous coil planet centrifuge with aqueous-aqueous polymer phase systems, J. Chromatogr. A, 1005 (2003) 103-112.

[14] K. Shinomiya, Y. Ito, Effects of the planetary motion of a coiled column on protein separation by the nonsynchronous coil planet centrifuge, J. Liq. Chromatogr. Rel. Techniq. 27 (2004) 3243-3255.

[15] I.A. Sutherland, G. Audo, E. Bourton, F. Couillard, D. Fisher, I. Garrard, P. Hewitson, O. Intes, Rapid linear scale-up of a protein separation by centrifugal partition chromatography, J. Chromatogr. A, 1190 (2008) 57-62.

[16] Y. Ito, Toroidal coil planet centrifuge, US Patent 4228009 (1980).

[17] S.D. Flanagan, G. Johansson, B. Yost, Y. Ito, I.A. Sutherland, Toroidal coil countercurrent chromatography in the affinity partitioning of nicotinic cholienergic receptor enriched membranes, J. Liq. Chromatogr. 7 (1984) 385-402.

[18] N.B. Mandava, Y. Ito, Plant hormone analysis by countercurrent chromatography, J. Liq. Chromatogr. 7 (1984) 303-322.

[19] K. Matsuda, S. Matsuda, Y. Ito, Toroidal coil counter-current chromatography: achievement of high resolution by optimizing flow-rate, rotation speed, sample volume and tube length, J. Chromatogr. A, 808 (1998) 95-104.

[20] Y. Ito, K. Matsuda, Y. Ma, L. Qi, Toroidal coil counter-current chromatography study of the mass transfer rate of proteins in aqueous-aqueous polymer phase system, J. Chromatogr. A, 802 (1998) 277-283.

[21] A. Rasooly, Y. Ito, Toroidal coil countercurrent chromatography separation of Staphylococcus aureus enterotoxin in food, J. Liq. Chromatogr. Rel. Technol. 21 (1998) 93-102.

[22] A. Rasooly, Y. Ito, Toroidal coil countercurrent chromatography separation and analysis of Staphylococcal enterotoxin A (SEA) in milk, J. Liq. Chromatogr. Rel. Technol. 22 (1999) 1285-1293.

[23] S. Matsuda, K. Matsuda, Y. Ito, Separation of phospholipids and glycolipids using analytical toroidal-coil counter-current chromatography. II. Comparison of the hydrophobicity between Mycoplasma fermentans and human-brain lipids, J. Liq. Chromatogr. Rel. Techniq. 26 (2003) 1135-1147.

[24] Y. Ito, Principle, apparatus, and methodology of high-speed countercurrent chromatography, in: Y. Ito, W.D. Conway (Eds.), High-speed countercurrent chromatography, Wiley, Chichester, 1996, pp. 3-44.

[25] I.A. Sutherland, P. Hewitson, R. Siebers, R. van den Heuvel, Y.H. Guan, L. Arbenz, J. Kinkel and D. Fisher, J. Scale-up of protein purifications using aqueous two-phase systems: 
Comparing multilayer toroidal coil chromatography with centrifugal partition chromatography, Chromatogr. A., 1218 (2011) 5527-5530

[26] Y.H. Guan, R. van den Heuvel, The three-dimensional model for helical columns on type-J synchronous counter-current chromatography, J. Chromatogr. A, 1218 (2011) 5108-5114.

[27] Y. Ito, F. Yang, P. Fitze, J. Powell, D. Ide, Improved spiral disk assembly for high-speed counter-current chromatography, J. Chromatogr. A, 1017 (2003) 71-81.

[28] Y. Ito, L. Qi, J. Powell, F. Sharpnack, H. Metger, J. Yost, X.-L. Cao, Y.-M. Dong, L.-S. Huo, X.-P. Zhu, T. Li, Mixer-settler counter-current chromatography with a barricaded spiral disk assembly with glass beads, J. Chromatogr. A, 1151 (2007) 108-114.

[29] K. Shinomiya, Y. Kabasawa, Y. Ito, Effect of elution modes on protein separation by crossaxis coil planet centrifuge with two different types of coiled columns, Prep. Biochem. Biotechnol., 29 (1999) 139-150.

[30] K. Shinomiya, Y. Kabasawa, Y. Ito, Protein separation by cross-axis coil planet centrifuge with spiral column assemblies, J. Liq. Chromatogr. Rel. Techniq., 25 (2002) 2665-2678.

[31] K. Shinomiya, K. Yanagidaira, Y. Ito, New small-scale cross-axis coil planet centrifuge: the design of the apparatus and its application to counter-current chromatographic separation of proteins with aqueous-aqueous polymer phase systems, J. Chromatogr. A, 1104 (2006) 245255.

[32] J.-I. Ikehata, K. Shinomiya, K. Kobayashi, H. Ohshima, S. Kitanaka, Y. Ito, Effect of Coriolis force on counter-current chromatographic separation by centrifugal partition chromatography, J. Chromatogr. A 1025 (2004) 169-175.

[33] Y. Guan, T.H. Lilley, T.E. Treffry, A new excluded volume theory and its application to the coexistence curves of aqueous polymer two-phase systems, Macromolecules 26 (1993) 3971-3979. 


\section{Legends to Figures}

Figure 1: Schematic views for constructing a toroidal column for J-type countercurrent chromatography and its dynamic usage.
(A) The helix coil is wound on a straight former (the former is usually taken away after the depicted helix coil is permanently formed);
(B) This helix coil is mounted on a CCC bobbin to form the toroidal column;
(C) The constructed toroidal coil on the bobbin undergoes the dynamic J-type planetary motion.

Figure 2: A stepwise experimentation for testing the protein separation potential with either the "12.5\% ATPS" and the "14\% ATPS" with a single bobbin of the 5-mm bore size toroidal coil on the J-type CCC device.

Figure 3: The effect of the column length of the wide bore toroidal column on protein separation with the use of the "12.5\% ATPS": (A) Single bobbin (i.e. Bobbin 2 or Column 2 in Table 1) with column length of $19.9 \mathrm{~m}$; (B) Double bobbin (i.e. Bobbins 1 plus 2 or Columns 1 \& 2 in Table 1) with column length of $39.8 \mathrm{~m}$.

Figure 4: Effects of the rotation speed of the rotor for the wide bore toroidal column on protein separation with the use of the " $12.5 \%$ ATPS".

Figure 5: Effects of the rotation speed of the rotor for the wide bore toroidal column on protein separation with the use of the " $14 \%$ ATPS".

Figure 6: The effect of mobile phase flow rate $(3.75$ and $5 \mathrm{ml} / \mathrm{min})$ on dipeptide separation using the " $12.5 \%$ ATPS" when operated on the 5-mm bore size toroidal coil on the J-type CCC device: (A) at $3.75 \mathrm{ml} / \mathrm{min}$ mobile phase flow rate, (B) at $5 \mathrm{ml} / \mathrm{min}$ mobile phase flow rate.

Figure 7: The chromatogram of repeated injection at 5 consecutive times. The ATPS contains $14 \%$ (w/w) PEG1000 and 14\% (w/w) potassium phosphate at $\mathrm{pH}$ 7. The other condition is: single bobbin with 333-ml column volume, rotor's rotation speed $1400 \mathrm{rpm}$, LP mobile with flow rate $20 \mathrm{ml} / \mathrm{min}$, each injection sample containing $2.2 \mathrm{mg} / \mathrm{ml}$ myoglobin and $2.2 \mathrm{mg} / \mathrm{ml}$ 
lysozyme respectively in the mobile phase, injected volume $16.8 \mathrm{ml}$ (i.e. $5 \%$ of the column volume), and mobile phase flow against the rotation of the bobbin. 


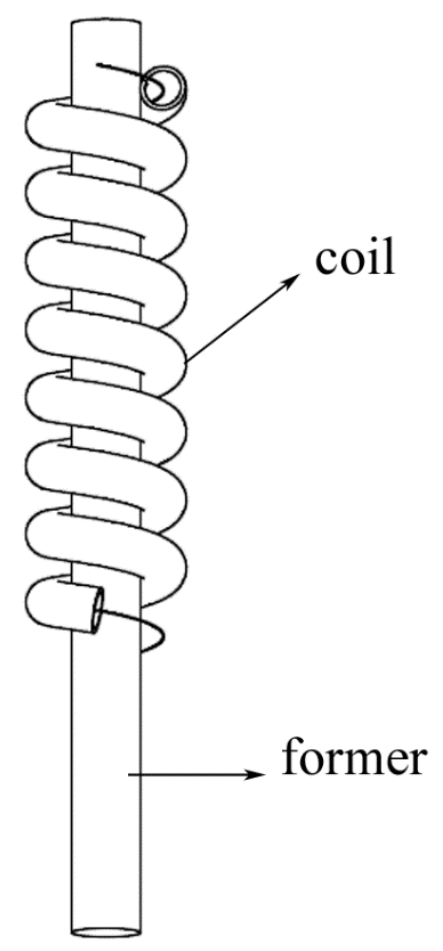

(A)

Figure 1A 


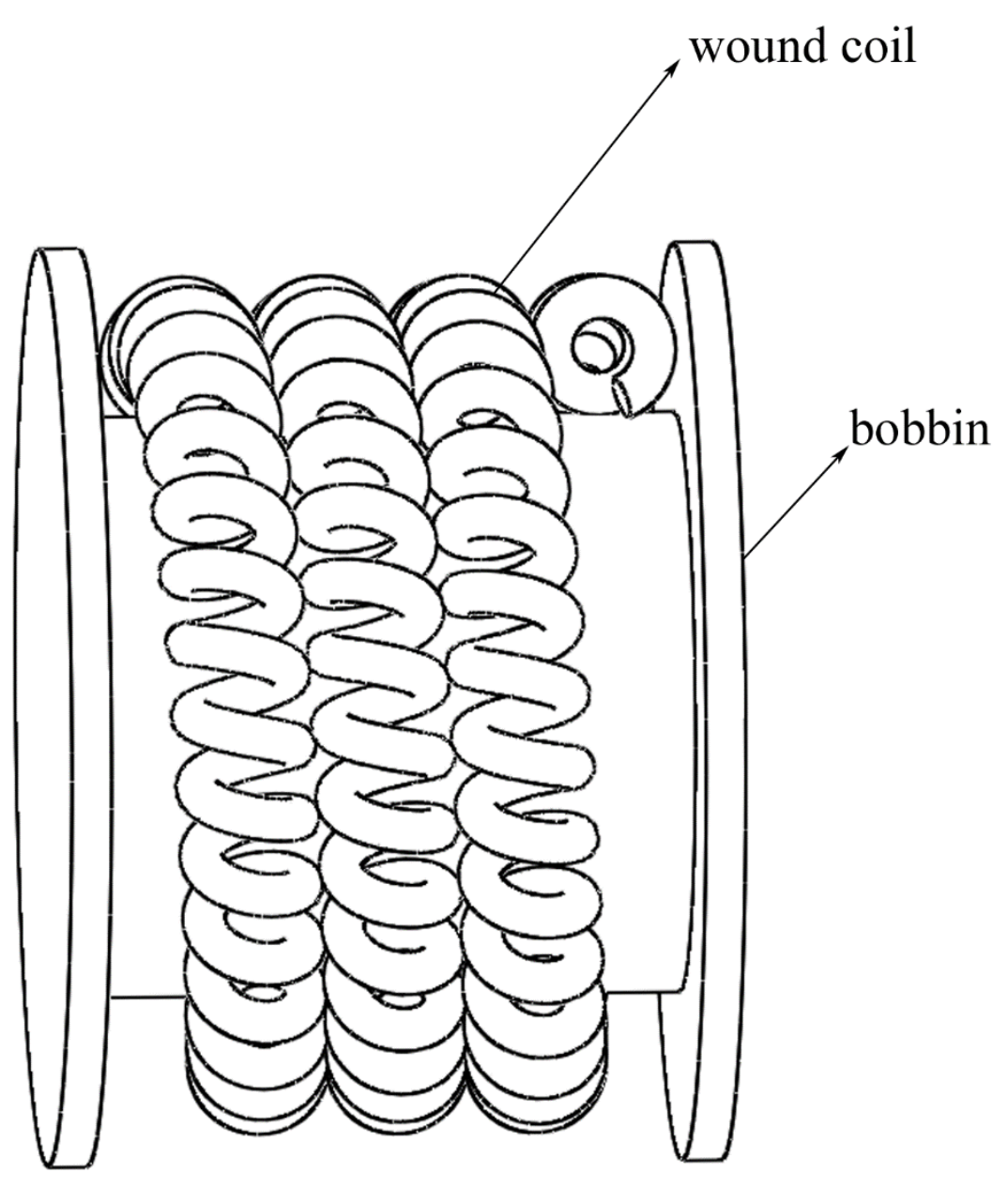

(B)

Figure 1B 


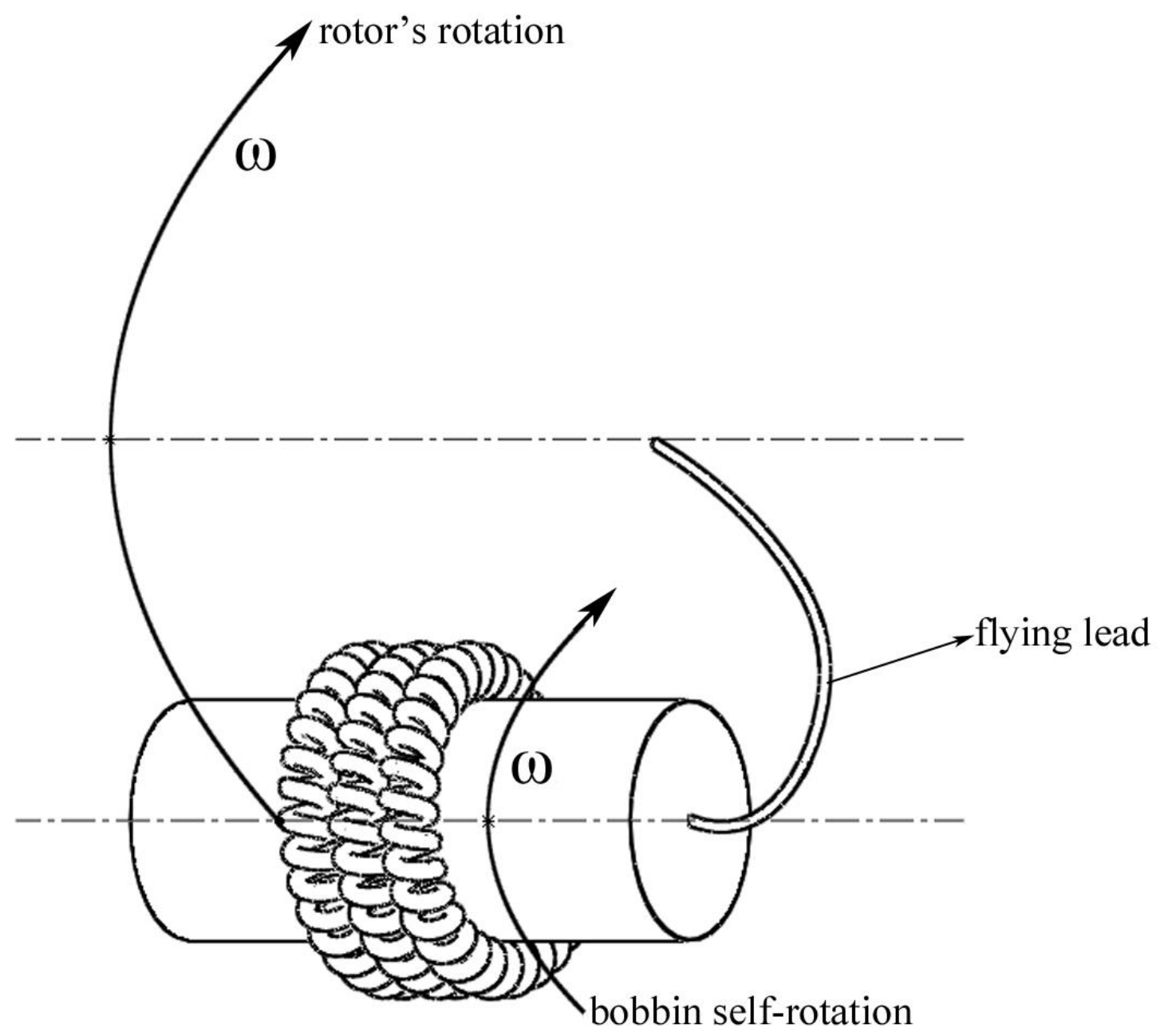

(C)

Figure 1C 


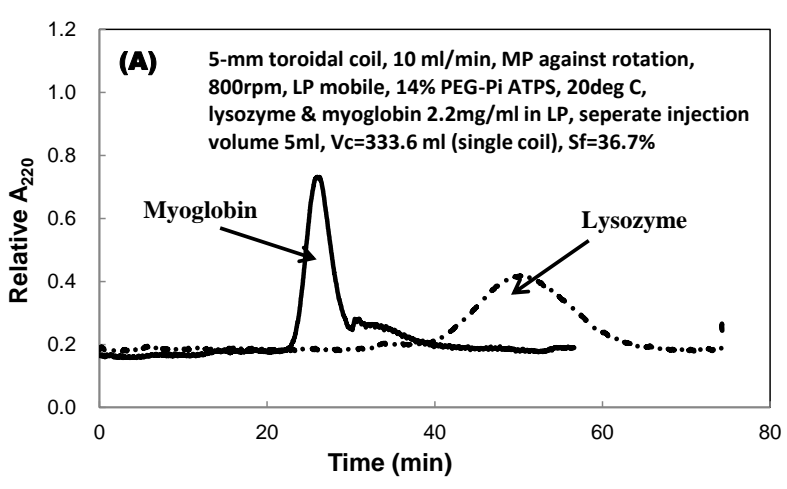

(A) Myoglobin and lysozyme are injected into the singlebobbin toroidal coil separately at mobile phase flow rate of $10 \mathrm{ml} / \mathrm{min}$ with the use of "the $14 \%$ ATPS".

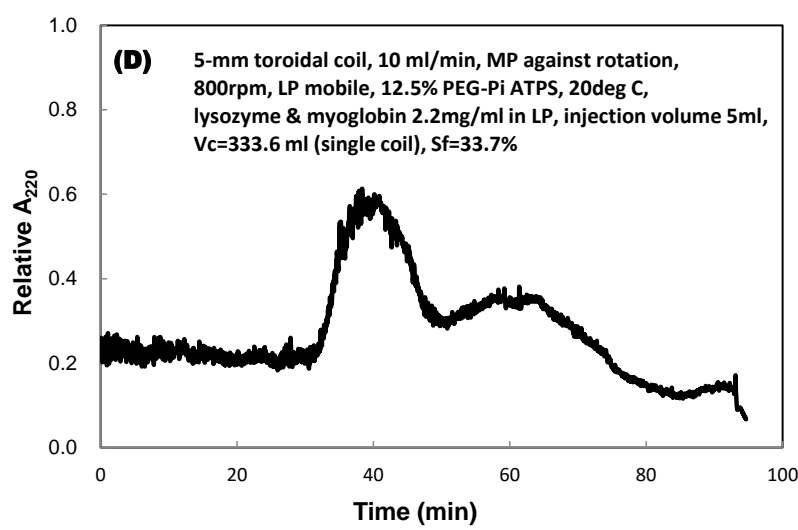

(D) Myoglobin and lysozyme are injected as a mixture into the single-bobbin toroidal coil at mobile phase flow rate of $10 \mathrm{ml} / \mathrm{min}$ with the use of "the $12.5 \%$ ATPS".

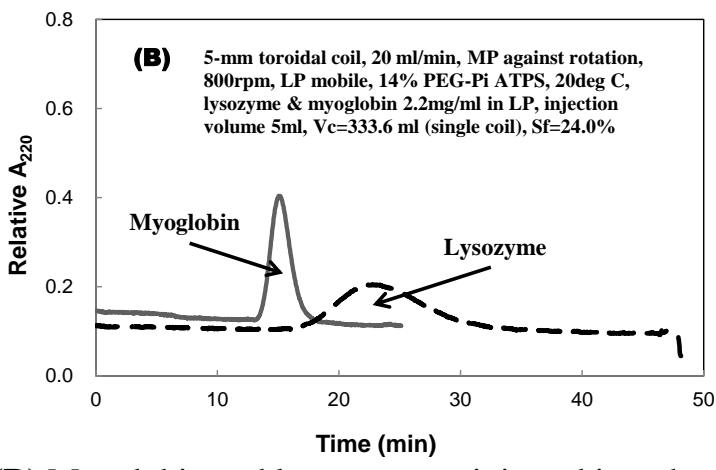

(B) Myoglobin and lysozyme are injected into the single-bobbin toroidal coil separately at mobile phase flow rate of $20 \mathrm{ml} / \mathrm{min}$ with the use of "the $14 \%$ ATPS".

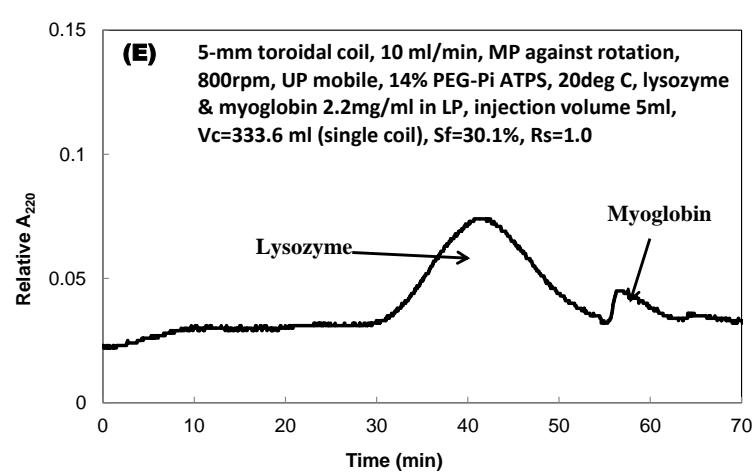

(E) Myoglobin and lysozyme are injected as a mixture into the single-bobbin toroidal coil at upper mobile phase flow rate of $10 \mathrm{ml} / \mathrm{min}$ with the use of "the 14\% ATPS".

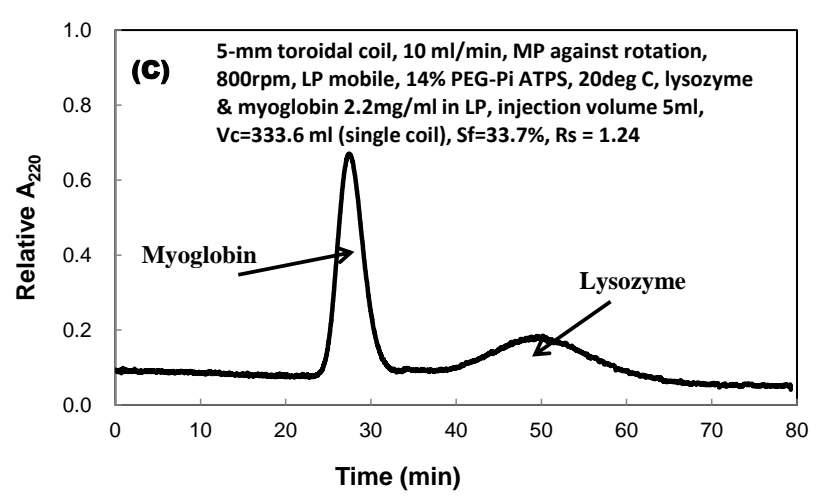

(C) Myoglobin and lysozyme are injected as a mixture into the single-bobbin toroidal coil at lower mobile phase flow rate of $10 \mathrm{ml} / \mathrm{min}$ with the use of "the 14\% ATPS".

\section{Figure 2}




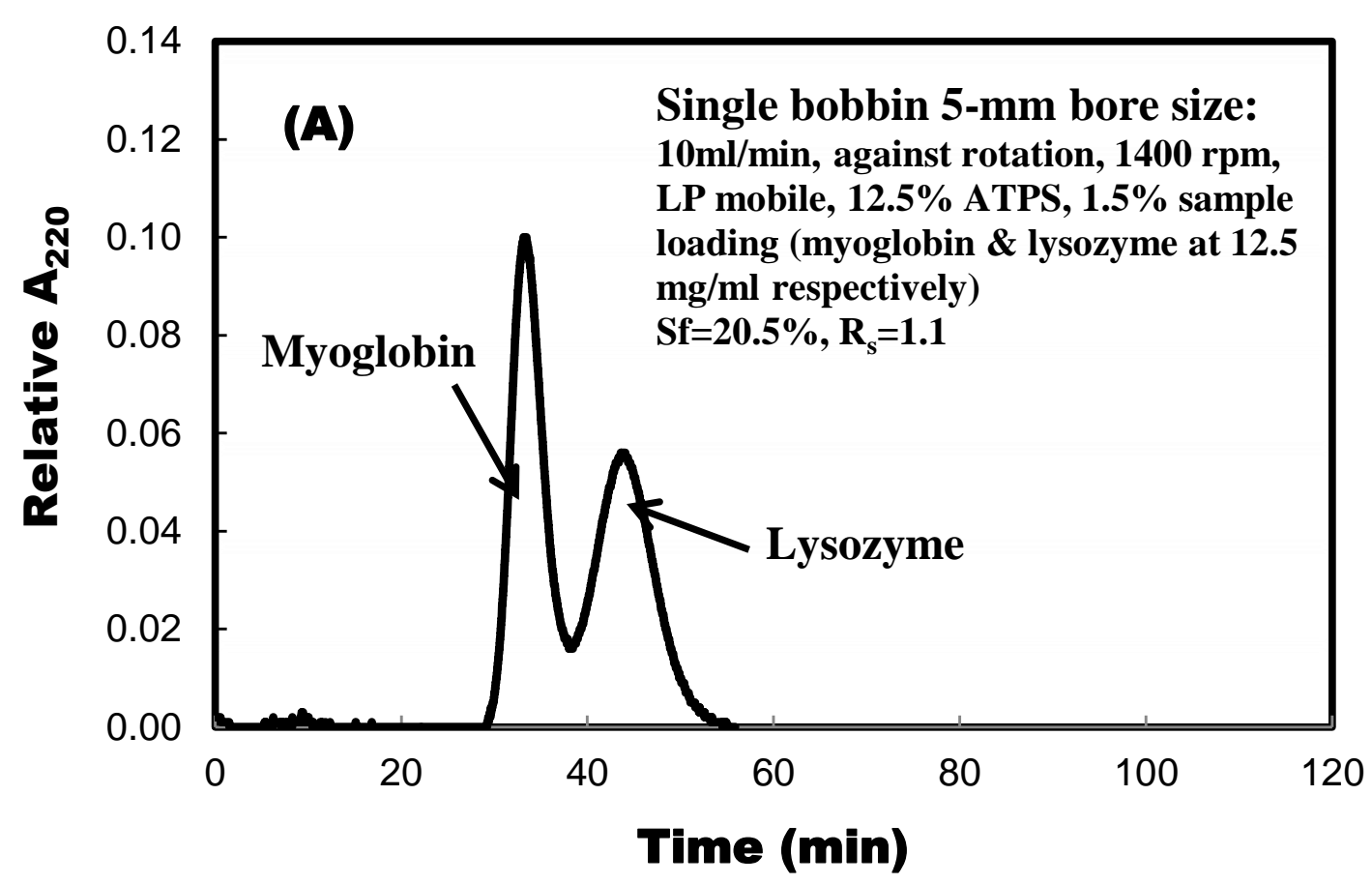

Figure 3A 


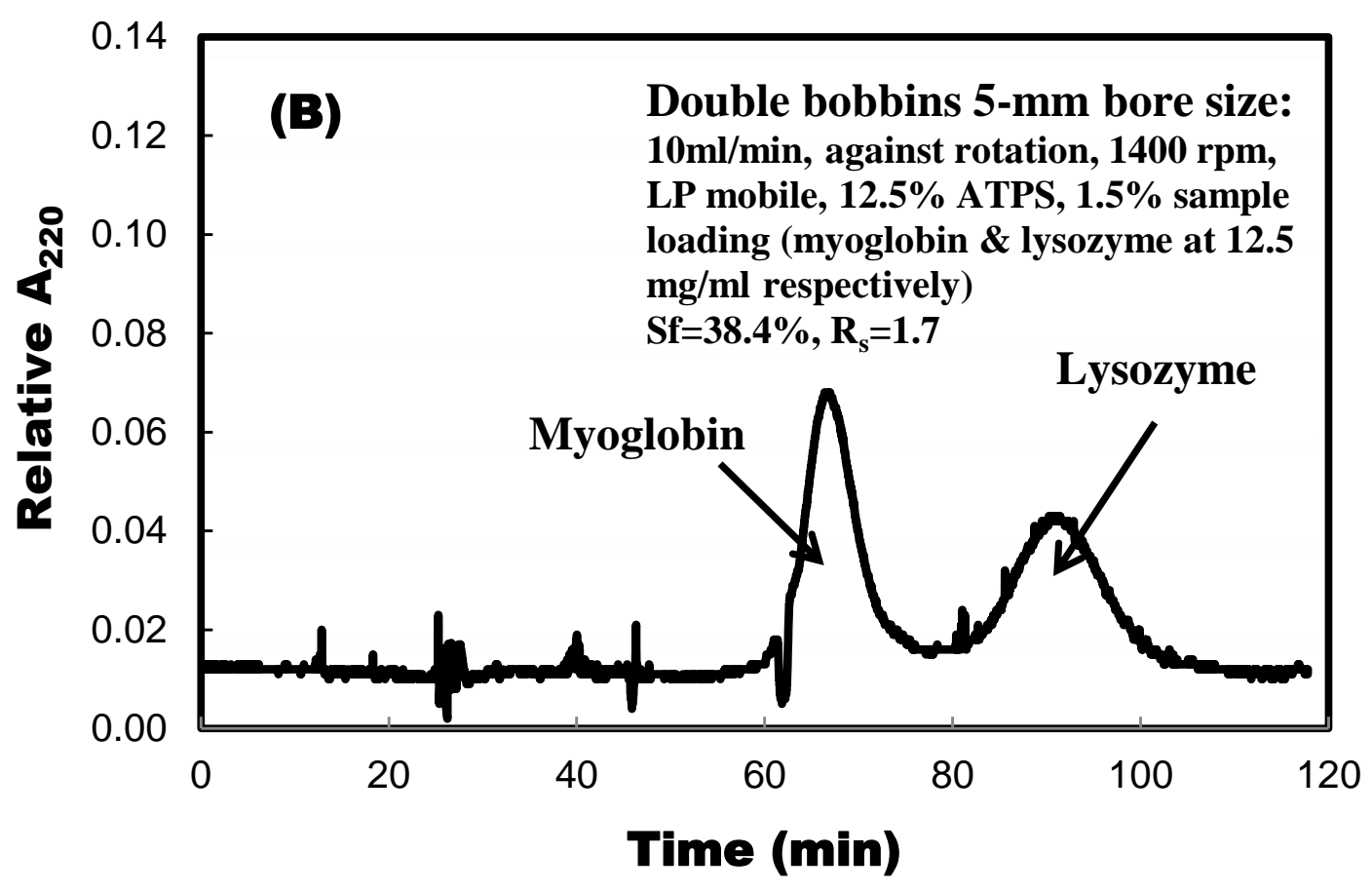

Figure 3B 

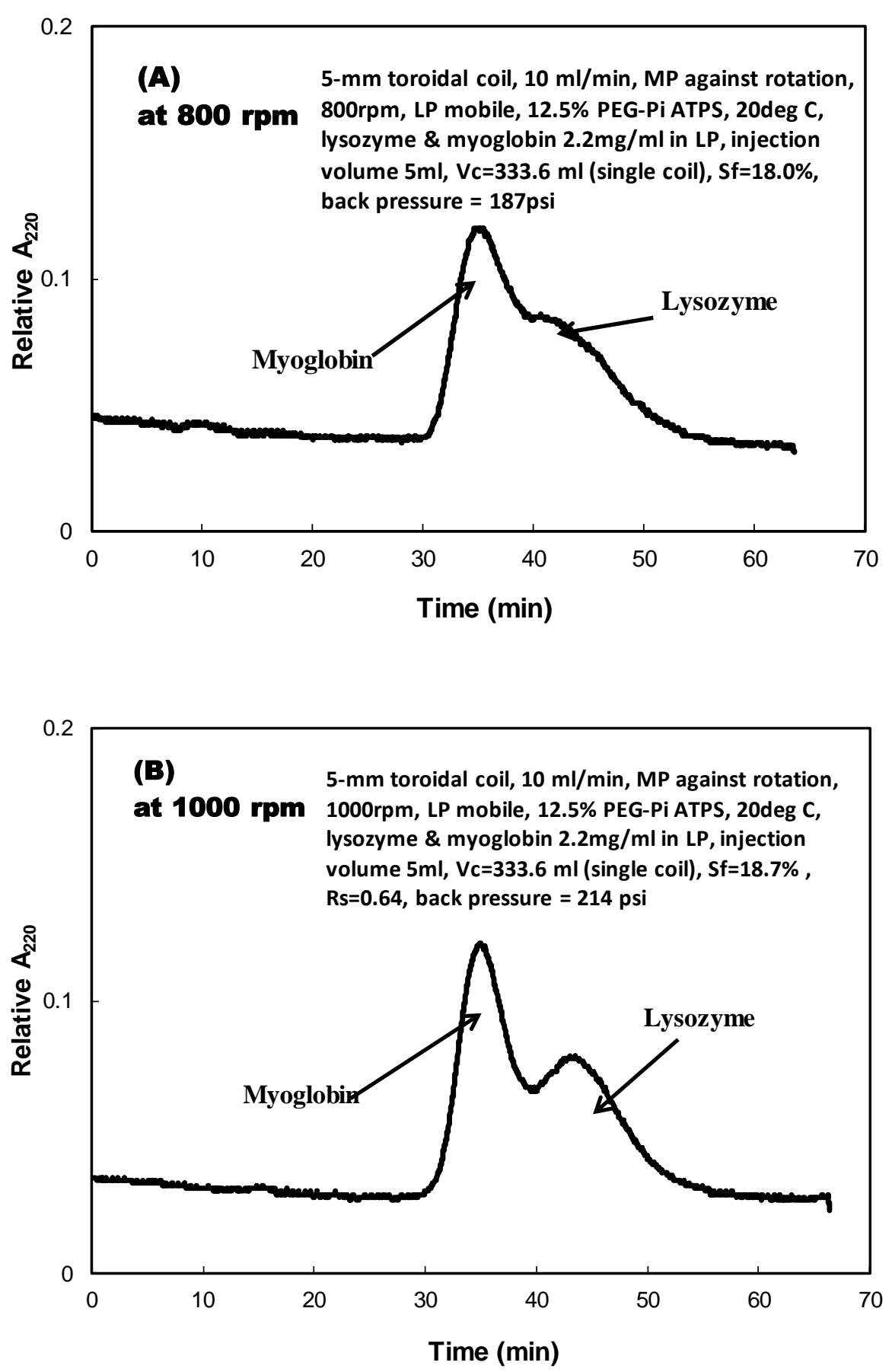

Figure 4 (Part 1) 

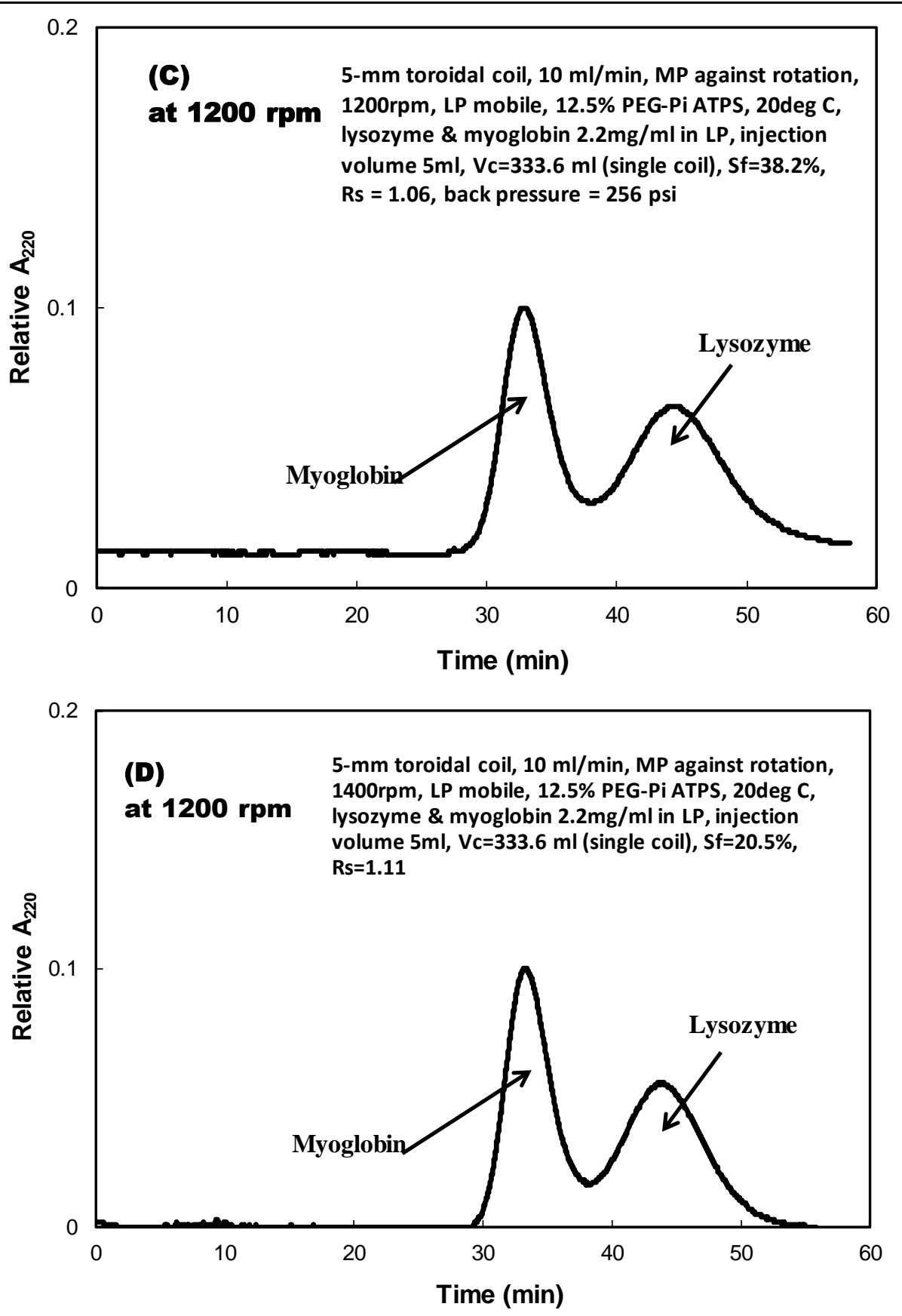

Figure 4 (Part 2) 

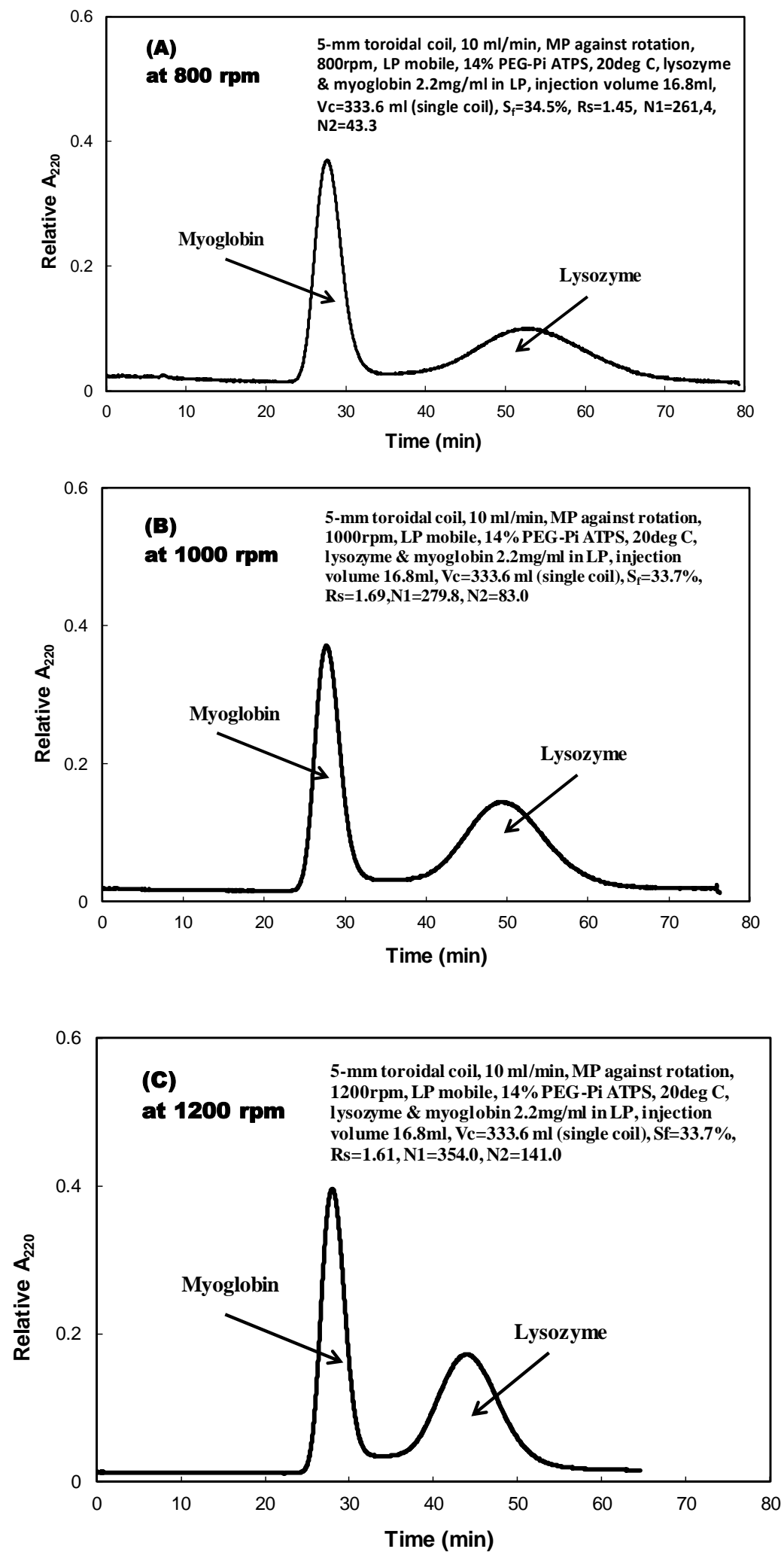

Figure 5 


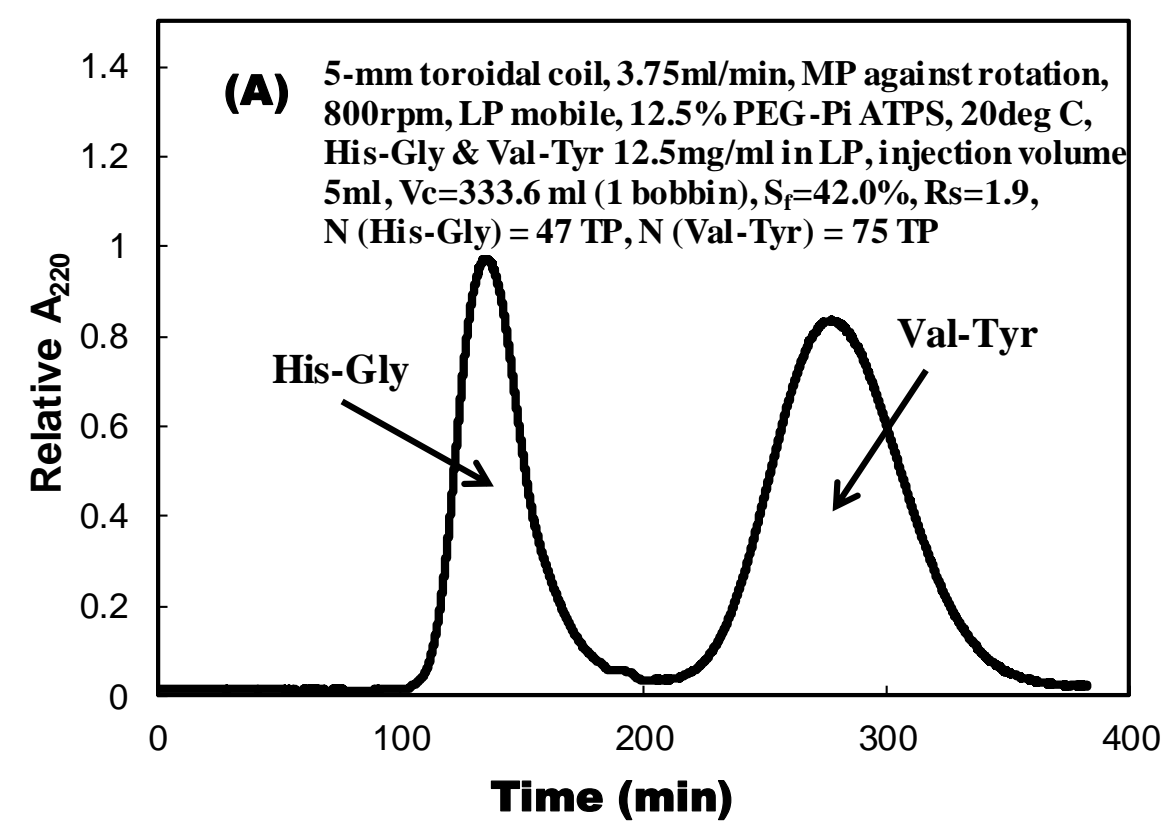

Figure 6A 


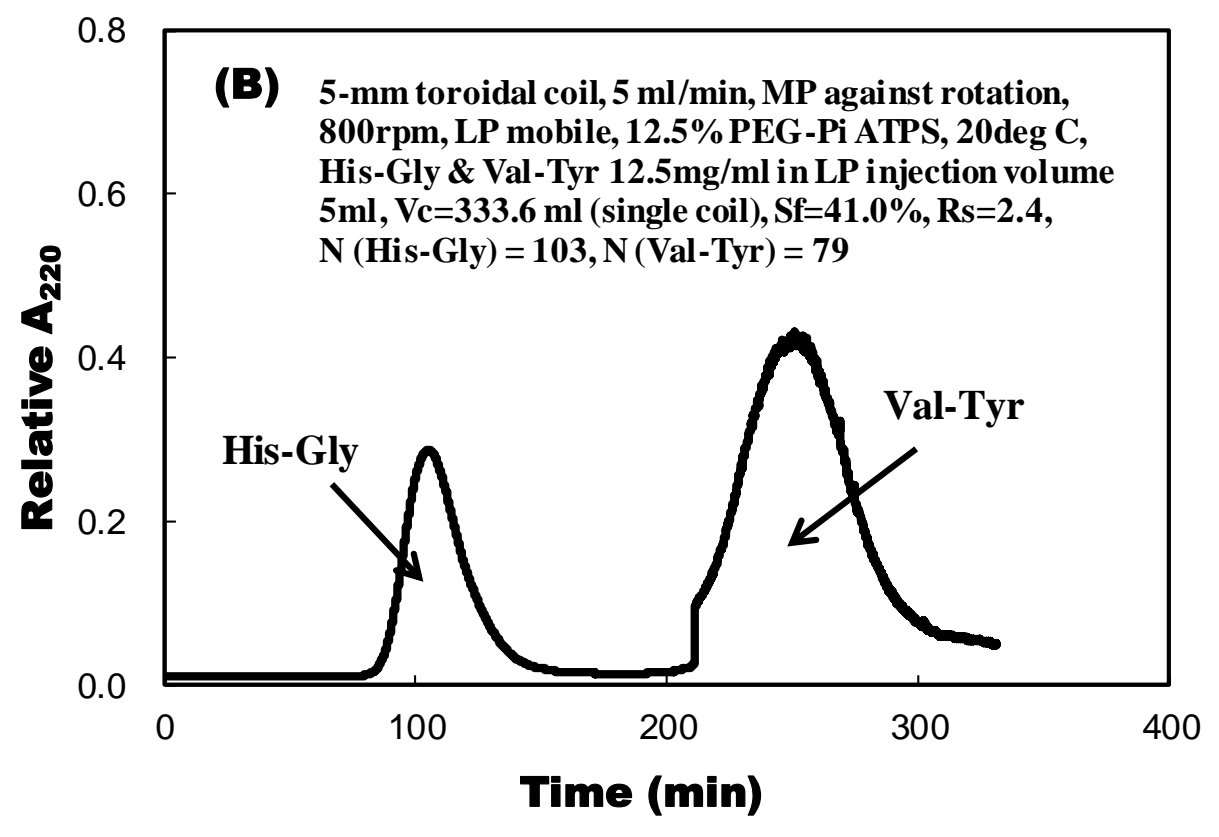

Figure 6B 


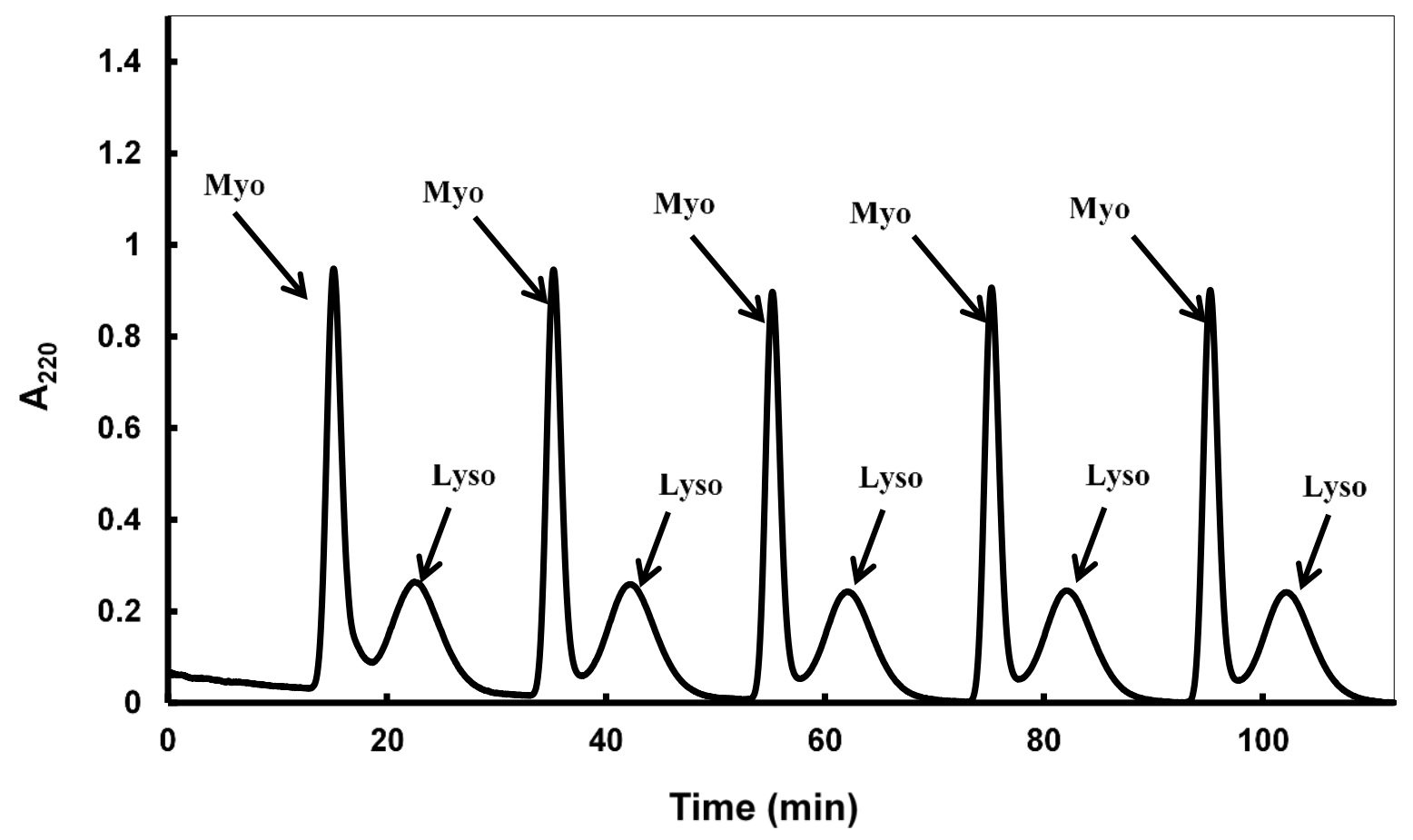

Figure 7 
Table 1: Comparison of the toroidal columns constructed in this work with those published in the literature

\begin{tabular}{|c|c|c|c|c|c|c|c|c|}
\hline & $\begin{array}{c}\text { Column } \\
\text { length } \\
(m) \\
\end{array}$ & $\begin{array}{c}\text { Column } \\
\text { volume } \\
(\mathrm{ml})\end{array}$ & $\begin{array}{c}\text { Bore } \\
\text { size } \\
(\mathrm{mm}) \\
\end{array}$ & Phase system & Samples for separation & $\begin{array}{l}\text { Flow rate of mobile } \\
\text { phase }(\mathrm{ml} / \mathrm{min})\end{array}$ & $\begin{array}{l}\text { Back pressure } \\
(\text { psi) }\end{array}$ & $\begin{array}{c}\text { Rotation } \\
\text { speed (rpm) }\end{array}$ \\
\hline $\begin{array}{l}\text { This work } \\
\text { (single bobbin) }\end{array}$ & 21.7 & 333.6 & 5 & $\begin{array}{l}\text { PEG1000/Potassium } \\
\text { Phosphate ATPS }\end{array}$ & Proteins & $\begin{array}{l}\text { LP mobile at 10- } \\
20 \mathrm{ml} / \mathrm{min}\end{array}$ & 130 psi & ca. 1200 \\
\hline $\begin{array}{l}\text { This work } \\
\text { (double bobbin) }\end{array}$ & 45.1 & 693.3 & 5 & $\begin{array}{l}\text { PEG1000/Potassium } \\
\text { Phosphate ATPS }\end{array}$ & Proteins & $\begin{array}{l}\text { LP mobile at } 10- \\
20 \mathrm{ml} / \mathrm{min}\end{array}$ & $276 \mathrm{psi}$ & ca. 1200 \\
\hline $\begin{array}{l}\text { Guan et al., 2009,2010 } \\
{[6,7]}\end{array}$ & 86.6 & 173.5 & 1.6 & PEG1000/K ${ }_{2} \mathrm{HPO}_{4}$ ATPS & Proteins & $\begin{array}{l}\text { LP mobile at } 0.62 \\
\mathrm{ml} / \mathrm{min}\end{array}$ & 245 psi & 800 \\
\hline $\begin{array}{l}\text { Guan et al., 2009,2010 } \\
{[6,7]}\end{array}$ & 53.5 & 107.1 & 1.6 & PEG1000/K ${ }_{2} \mathrm{HPO}_{4}$ ATPS & Proteins & $\begin{array}{l}\text { LP mobile at } 0.62-1.25 \\
\mathrm{ml} / \mathrm{min}\end{array}$ & ca. $250 \mathrm{psi}$ & 800 \\
\hline $\begin{array}{l}\text { Guan et al., 2009,2010 } \\
{[6,7]}\end{array}$ & 25.7 & 51.5 & 1.6 & PEG1000/K ${ }_{2} \mathrm{HPO}_{4}$ ATPS & Proteins & $\begin{array}{l}\text { LP mobile at } 0.62-1.25 \\
\mathrm{ml} / \mathrm{min}\end{array}$ & ca. $110 \mathrm{psi}$ & 800 \\
\hline Ito \& Ma, 1998 [3] & 20 & $12.8-20$ & 1.07 & $\mathrm{PEG} 1000 / \mathrm{K}_{2} \mathrm{HPO}_{4}$ & Proteins & UP mobile at $3-12 \mathrm{ml} / \mathrm{h}$ & Not available & 1200 \\
\hline Flanagan et al., 1984 [17] & 14 & 8.5 & 1.07 & $\begin{array}{c}\text { PEG-ligand/Dex500 } \\
\text { ATPS }\end{array}$ & $\begin{array}{l}0.5 \mathrm{ml}, 0.72 \mathrm{mg} / \mathrm{ml} \text { total } \\
\text { membrane protein }\end{array}$ & $14 \mathrm{ml} / \mathrm{h}$ & Not available & 1200 \\
\hline Rasooly \& Ito, 1998 [21] & 20 & 18 & 1 & PEG1000/K $\mathrm{K}_{2} \mathrm{HPO}_{4}$ ATPS & $\begin{array}{c}0.5 \mathrm{ml}, 7.5 \mu \mathrm{g} / \mathrm{ml} \\
\text { Staphylococcal enterotoxin A }\end{array}$ & $12 \mathrm{~m} / \mathrm{h}, \mathrm{LP}$ mobile & Not available & 1200 \\
\hline Mandava \& Ito, 1984 [18] & 50 & 18 & 0.55 & $\begin{array}{l}\text { Chloroform/acetic } \\
\text { acid/water }\end{array}$ & Plant hormones & $\begin{array}{l}\text { Org. phase mobile at 2- } \\
\qquad 4 \mathrm{ml} / \mathrm{hr}\end{array}$ & $400-500$ & $400-500$ \\
\hline Rasooly \& Ito, 1999 [22] & 60 & 13 & 0.55 & PEG1000/K $\mathrm{K}_{2} \mathrm{HPO}_{4}$ ATPS & $\begin{array}{c}0.5 \mathrm{ml}, \text { with } 100 \mathrm{ng} / \mathrm{ml} \\
\text { Staphylococcal enterotoxin A }\end{array}$ & $12 \mathrm{ml} / \mathrm{h}$ LP mobile & Not available & 1200 \\
\hline Matsuda et al., 1998 [19] & 100 & 11 & 0.4 & $\begin{array}{l}\text { Chloroform/acetic } \\
\text { acid/HCl }\end{array}$ & DNP-amino acid & $\begin{array}{l}\text { UP or LP mobile at } \\
0.6 \mathrm{ml} / \mathrm{h}\end{array}$ & Not available & 800 \\
\hline Matsuda et al., 2003 [23] & 60 & 8 & 0.4 & $\begin{array}{l}\text { Hexane/ethyl acetate/ } \\
\text { ethanol/0.1\% aq. NH3 }\end{array}$ & Lipids & $\begin{array}{l}\text { UP or LP mobile at } \\
66 \mathrm{ml} / \mathrm{h}\end{array}$ & Max 350 & $700-1500$ \\
\hline Ito \& Bowman, 1978 [11] & 24 & 3 & 0.38 & $\begin{array}{l}\text { Chloroform-acetic acid- } \\
0.1 \mathrm{M} \mathrm{Cl}\end{array}$ & $\begin{array}{l}20 \mu 1,0.25-0.5 \% \text { each DNP- } \\
\text { amino acid }\end{array}$ & $\mathrm{LP}$ mobile at $0.3 \mathrm{ml} / \mathrm{h}$ & Not available & 750 \\
\hline
\end{tabular}

